\title{
Turkey Wattle Temperature Response to Distinct Environmental Factors
}

\section{-Author(s)}

\section{Mendes AS \\ Moura DJ" \\ Morello GM"II \\ Carvalho TMR" \\ Sikorski RR'}

Department of Agronomy. Technological Federal University of Paraná, Dois Vizinhos, PR, Brazil.

" Departamento de Construções Rurais e Ambiência. Universidade Estadual de Campinas, Campinas, SP, Brasil.

III Purdue University, West Lafayette, IN, U.S.A.

\section{ABSTRACT}

Rearing environmental conditions are important for turkey production, because this bird is particularly sensitive to heat stress. This study aimed at measuring the wattle temperature response of turkeys of three different ages $(61,96$, and 131 days old) exposed to different combinations of dry bulb temperature, relative humidity, and wind speed ranges, as an indication of their physiological responses. The experiment was conducted with 42 male birds housed in a controlled environment chamber and exposed to different combinations of two air speed (WS) ranges $\left(W_{1}=0.3-0.6 \mathrm{~ms}^{-1}\right.$, considered low, and $\mathrm{WS}_{2}=1.2$ $1.6 \mathrm{~ms}^{-1}$, considered high), dry bulb temperature (DBT) between 22 and $34{ }^{\circ} \mathrm{C}$, and relative humidity (RH) between 40 to $90 \%$. The statistical analysis showed that WS, DBT, and RH significantly influenced wattle temperature of 61-d-old turkeys, while only WS and DBT influenced this response when turkeys were 96 days old. Furthermore, DBT was highly correlated with both low and high WS. In 131-day-old turkeys, WT response was virtually the same at both wind speed ranges when high DBT was applied. Turkey wattle temperature was influenced by wind speed, and was dependent on both environmental dry bulb temperature and relative humidity, as well as bird age.

\section{INTRODUCTION}

The Brazilian turkey production has expanded in the last 25 years. In 2013 , turkey meat production totaled 364,000 tons (79 \% fresh and $21 \%$ processed meat), out of each 161,000 tons were exported. Brazil is currently the third producer (following the USA and the EU) and the second exporter (after the USA) of turkey meat (UBABEF, 2014).

In the last decades, fast-growing meat-type turkey shave shown significant improvements in growth performance, feed conversion ratio, and livability (Havenstein et al., 2007), mainly due to intensive genetic selection. These improvements, however, have also resulted in a significant increase in heat production by these birds, which have shown difficulties in coping with extreme environmental conditions, consequently impacting their productivity. Birds dissipate heat through respiratory/evaporative mechanisms, acutaneous evaporative mechanism, and sensible heat loss (SHL) via radiation, convection, and conduction (Yahav et al., 2011). Wattle temperature may be used as an indication of thermal comfort, and environmental conditions influence wattle temperature (Morello et al., 2007). For many years, research has focused on the effects of air temperature (Ta) (Hurwitz \& Bengal, 1982; Yahavand Plavnik, 1999; Yahav et al., 2000a) and, to a lesser extent, of relative humidity $(\mathrm{RH})$ (Yahav et al., 1995, 1998; Yahav, 2000b) on the performance and thermoregulation of young and mature turkeys. Only recently the interest shifted towards the effects of ventilation rate (VR) on the thermoregulation and performance of turkeys. This shift was driven 


\section{Turkey Wattle Temperature Response to Distinct Environmental Factors}

Agricultural Engineering College (FEAGRI), UNICAMP, Campinas, SP, Brazil, located at $2^{\circ} 254^{\prime} S$ latitude, $47^{\circ}$ 05' W longitude, and $674 \mathrm{~m}$ altitude.

Forty-two male turkeys (14 birds with 61 days old, 14 birds with 96 days old, and 14 birds with 131 days old) were submitted to the experimental treatments shown in Table 1.The birds derived from a commercial turkey farm located in Uberlândia, state of Minas Gerais, Brazil. Upon arrival to the experimental facilities, with 54, 89 and 124 days of age, birds were housed under thermoneutral temperature for a week in order to minimize the stress, after which they were placed inside the environmental chamber at a stocking density of 2.8 birds $\mathrm{m}^{-2}$. All birds of each age group were exposed to the 14 different combinations of dry bulb temperature (DBT) and relative humidity $(\mathrm{RH})$ shown in Table 1. Birds were submitted to each treatment (DBT $+\mathrm{RH}$ combination) for 90 minutes, with an interval of 10 min between treatments, during which the thermoneutral conditions were re-established. Each bird was counted as a separate event

Table 1 - Combinations of dry bulb temperature and relative humidity ranges applied both at wind speeds used in the present experiment (WS : 0.3-0.6 $\mathrm{m} \mathrm{s}^{-1}$ and $\mathrm{WS}_{2}$ : 1.2-1.6 $\left.\mathrm{m} \mathrm{s}^{-1}\right)$.

\begin{tabular}{ll}
\hline DBT limit range $\left({ }^{\circ} \mathrm{C}\right)$ & RH limit range $(\%)$ \\
\hline$[22-25]$ & {$[40-50] ;[60-70] ;[70-80] ;[80-90]$} \\
{$[25-28]$} & {$[40-50] ;[60-70] ;[70-80] ;[80-90]$} \\
{$[28-31]$} & {$[50-60] ;[60-70] ;[70-80] ;[80-90]$} \\
\hline $31-34]$ & {$[70-80] ;[80-90]$} \\
\hline
\end{tabular}

The environmental temperature was maintained constant during each assay by the use of a cooler and a heater with a thermal resistance, which enabled a 5 to $40^{\circ} \mathrm{C}$ temperature range (Figure 1a). A humidifier fixed on the ceiling was used to increase relative humidity, and a dehumidifier to decrease it (Figure $1 \mathrm{~b}$ ). Two wind speed (WS) ranges were applied: $W_{1}=0.3-0.6 \mathrm{~ms}$ 1 , which was considered as low, and WS $=1.2-1.6$ $\mathrm{ms}^{-1}$, which was considered as high. Wind speed was changed using two positive pressure fans (140 W, 127 $\mathrm{V}, 1.1 \mathrm{~A}$ ) (Figure 1c). All equipment was connected to a computer and controlled by a software (Figure 1d).

Data relative to DBT and WS were recorded manually using a thermo-anemometer with hot wire (model9555, VelociCalc ${ }^{\circledR}, \mathrm{TSI}_{\mathrm{TM}^{\prime}}$ Shoreview, USA), and RH data using a hygrometer (model THDL 400, Instrument ${ }^{\circledR}$, Sao Paulo, Brazil). Wattle temperature (WT) was measured during the last 10 minutes for each treatment. Therefore, the treatment effects were measured directly on the birds, using an infrared thermometer (OS530 model,
The experiment was carried out in an environmentally controlled chamber located at the 
a

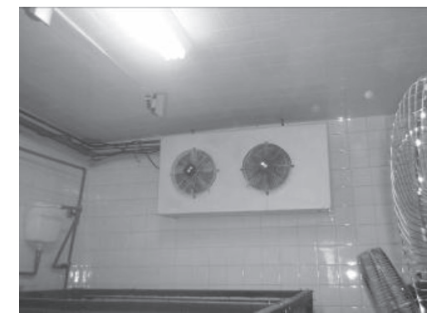

b

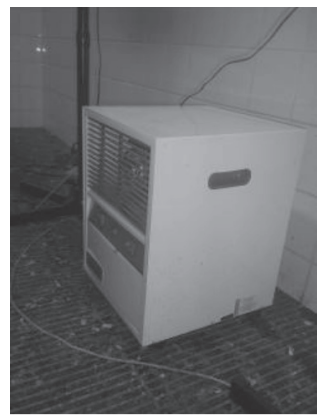

C

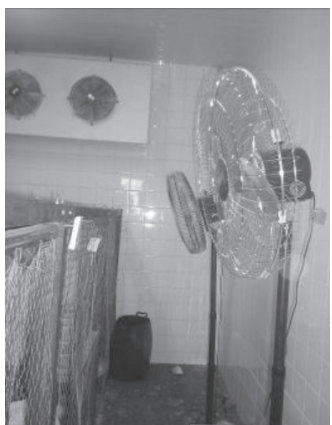

d

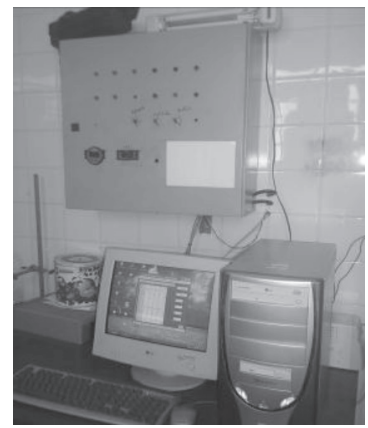

Figure 1. Equipment used to control the environmental conditions inside the chamber: (a) cooler; (b)dehumidifier; (c) fan; (d) controlsoftware.

Omega ${ }^{\circledR}$ OS530, Stamford, USA; Figure 2). There were 14 replicates per treatment per age.

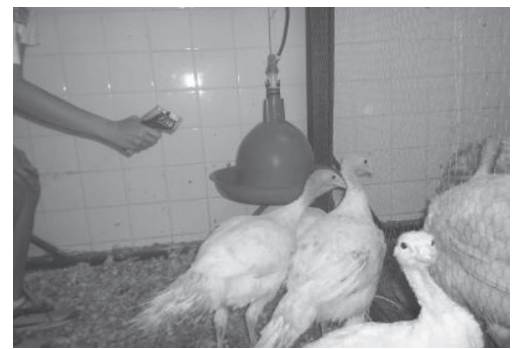

Figure.2..Infrared temperature reading of the turkeys' wattle during the trial.

Data were submitted dummy-variable regression analysis to verify the influence and the correlation between wind speed and turkey wattle temperature as a function of the applied DBT and RH combinations (Table 1). The software used for statistical analysis was MINITAB (2005).

\section{RESULTS AND DISCUSSION}

The results of the interactions between DBT, RH, and WS are presented according to turkeys' age (61, 96 and 131 days old, respectively).

61-day-old turkeys: The statistical analysis showed that the variables WS, DBT, and RH significantly affected ( $p \leq 0.000$ ) the wattle temperature of 61-d-old turkeys $\left(\mathrm{WT}_{61}\right)$. The following equation describes the variation of wattle temperature as function of WS, DBT, and RH (Eq. 1).

$\mathrm{WT}_{61}=19.06+7.01_{(\mathrm{WS} 1)}+0.33 * \mathrm{DBT}+0.08 * \mathrm{RH}-$ 0.12 * $\mathrm{DBT}_{(\mathrm{ws} 1)}-0.05 * \mathrm{RH}_{(\mathrm{ws} 1)}\left(\mathrm{R}^{2}=0.68\right)$ Eq. 1

The model shows an interaction between WS and both DBT and RH. Figures 3 and 4 show the influence of $\mathrm{RH}$ and DBT on wattle temperature according to two different WS ranges: 0.3 to 0.6 (WS $)$ and 1.20 to $1.60 \mathrm{~ms}^{-1}\left(\mathrm{WS}_{2}\right)$. The results indicated that only $\mathrm{RH}$ significantly interacted with $\mathrm{WS}_{1}$, suggesting that increasing wind speed does affect the thermal response of 61-day-old turkeys reared in a closed environment. Although the use of evaporative cooling is often used by turkey producers in Brazil and other tropical regions, the obtained results indicate that low ventilation rates may be sufficient to reduce internal $\mathrm{RH}$ values, in agreement with the recommendations of Bottcher \& Czarick (1997) and Gates et al. (1998) for broiler houses.

Although wattle temperature dispersion was similar between the two applied WS (Figure 3), the slope of the lines indicates that $\mathrm{RH}$ had a stronger influence on WT at the range of high wind speed (1.2 to $\left.1.6 \mathrm{~ms}^{-1}\right)$. Figure 4 shows that there was an interaction between the variables DBT and $W T(p<0.05)$, according to the line slope of WS. The line slope shows that both DBT and RH influenced turkey wattle temperature at both WS ranges. Czarick (2006) reported that head surface and body temperatures of broilers increased proportionally to the increase in internal broiler house temperature, as also shown in the present study, where it was found that WT temperature increased with DBT $(p<0.05)$, DBT influenced the increase in WT for this specific experiment.

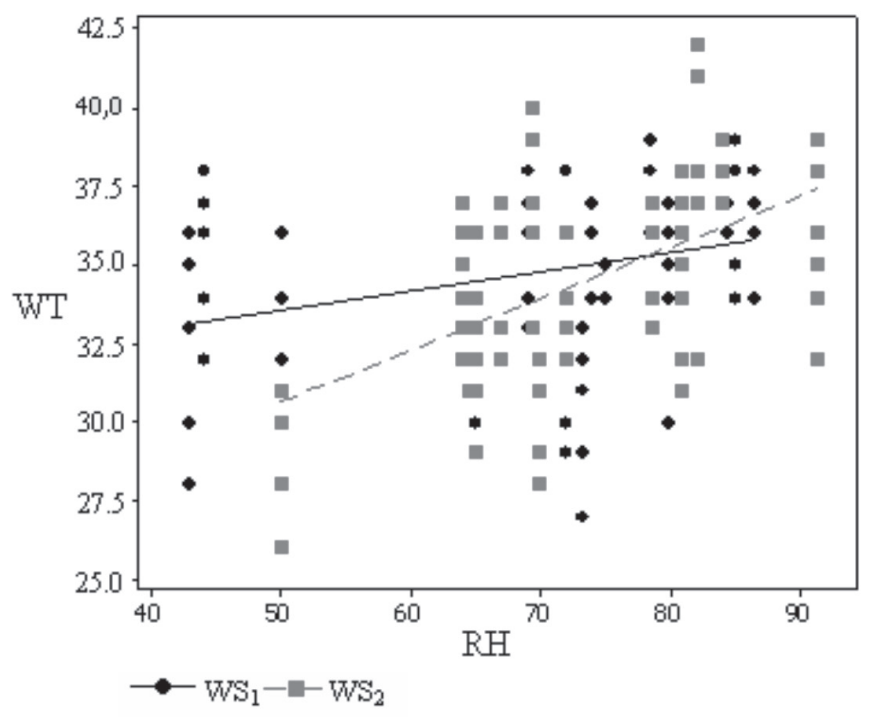

Figure 3. Influence of relative humidity on the wattle temperature of 61-day-old turkeys at two wind speed ranges $\left(W S_{1}=0.3\right.$ to $0.6 \mathrm{~m} \mathrm{~s}^{-1}$ and $W S_{2}=1.2$ to $\left.1.6 \mathrm{~m} \mathrm{~s}^{-1}\right)$. 


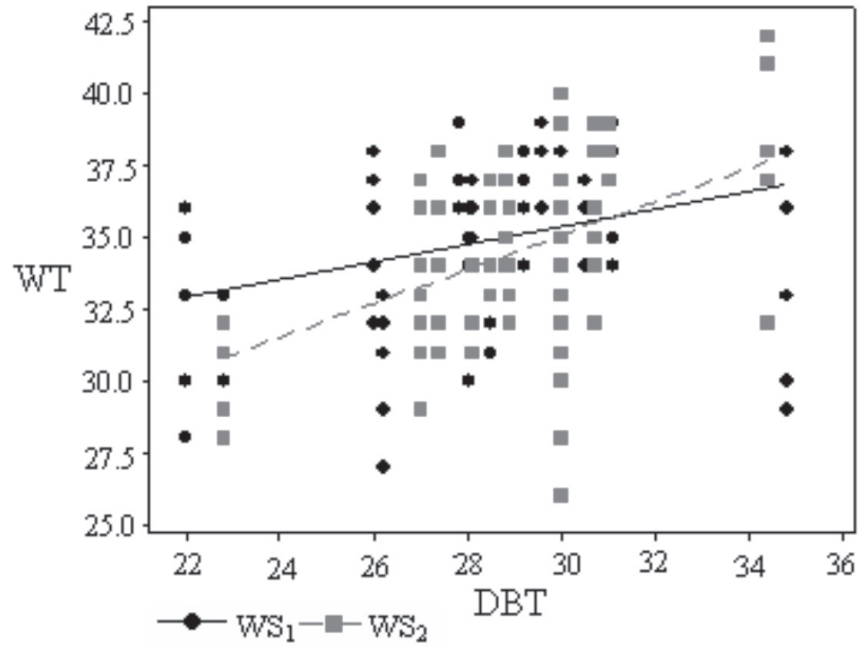

Figure 4. Influence dry bulb environmental temperature on the wattle temperature of 61-day-old turkeys at two wind speed ranges $\left(W S_{1}=0.3\right.$ to $0.6 \mathrm{~m} \mathrm{~s}^{-1}$ and $\mathrm{WS}_{2}=1.2$ to $\left.1.6 \mathrm{~m} \mathrm{~s}^{-1}\right)$.

Turkeys are known to be less sensitive than broilers to changes in environmental conditions (Yahav, 2000a) and their body temperature $\left(40.6\right.$ to $\left.41.5^{\circ} \mathrm{C}\right)$ is at the lowest end of the range determined for domestic fowl (Prinzinger et al., 1991). The fact that the body temperature of turkeys was not affected by the highest DBT $\left(35^{\circ} \mathrm{C}\right)$ may be explained by their better thermoregulation capability compared with broiler chickens, which showed significantly higher body temperature when exposed to the same environmental temperatures (42.8 to $43.9^{\circ} \mathrm{C}$; Yahav et al., 2004).

96-days-turkeys: The statistical analysis showed that both WS and DBT influenced turkey wattle temperature response $(p \leq 0.000)$. Relative humidity did not affect WT. Equation 2 describes the model that associates turkey wattle temperature with the evaluated environmental factors.

$$
\begin{aligned}
& \mathrm{WT}_{96}=21.57+5.54_{(\mathrm{WS} 1)}+0.499 * \mathrm{DBT}-0,17 \\
& { }^{*} \mathrm{DBT}_{\text {(wS1) }} \quad\left(\mathrm{R}^{2}=0.63\right) \mathrm{Eq} .2
\end{aligned}
$$

The variables WS and DBT were highly and positively correlated with WT $(p \leq 0.000)$, but not RH. Figure 5 presents an interaction between $\mathrm{WS}_{1}$ and $\mathrm{RH}$. Fig. 5 and 6 show the influence of RH and DBT on WT at both wind speed ranges. Ventilation moves the air around the birds increasing their critical effective temperature upper limit and resistance to thermal stress (Bottcher \& Czarick, 1997; Aradas et al., 2005), and has a positive effect on their physiological parameters, particularly when environmental temperature reaches levels above the thermoneutral zone $\left(>25^{\circ} \mathrm{C}\right)$.

In Figure 5, the line that represents the WT response to $\mathrm{RH}$ at both wind speed ranges presents a horizontal profile, indicating that $\mathrm{RH}$ did not influence the WT of 96-day-oldturkeys. Furthermore, both lines have the same slope, which indicates that there was no significant interaction between $\mathrm{RH}$ and WT at WS, or $\mathrm{WS}_{2}$.

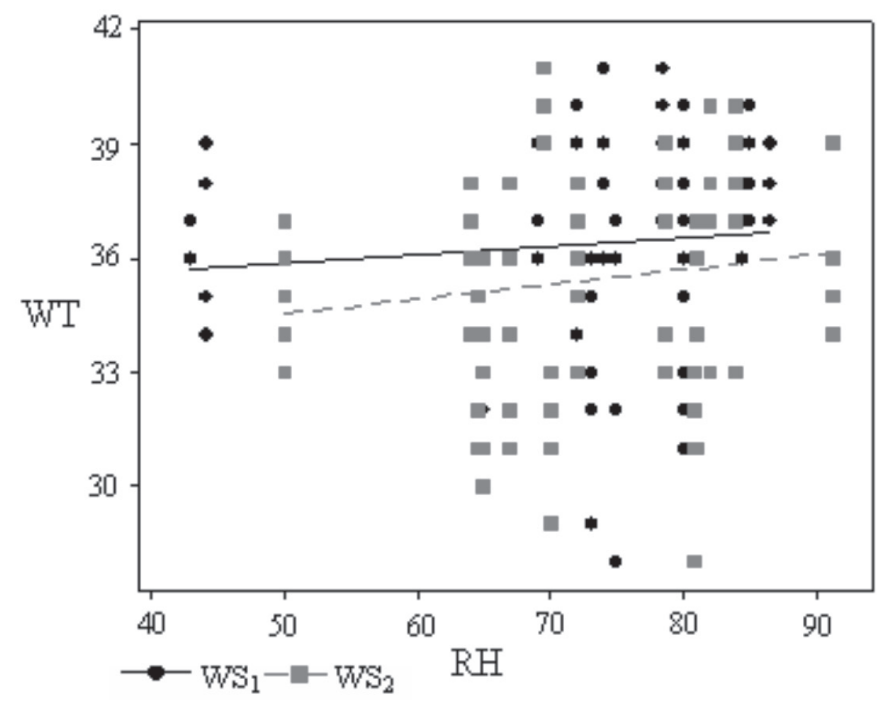

Figure 5. Influence of relative humidity on the wattle temperature of 96-day-old turkeys at two wind speed ranges ( $W S_{1}=0.3$ to $0.6 \mathrm{~m} \mathrm{~s}^{-1}$ and $W_{2}=1.2$ to $1.6 \mathrm{~m} \mathrm{~s}^{-1}$ ).

Figure 6 shows that DBT was highly correlated with WT at both low and high wind speeds, as the slopes of the lines are steeper. There was also an interaction between DBT and WS, as shown by the significantly different slopes for similar data dispersion, which is in agreement with previous studies(Czarick, 2006; Aradas et al., 2005).

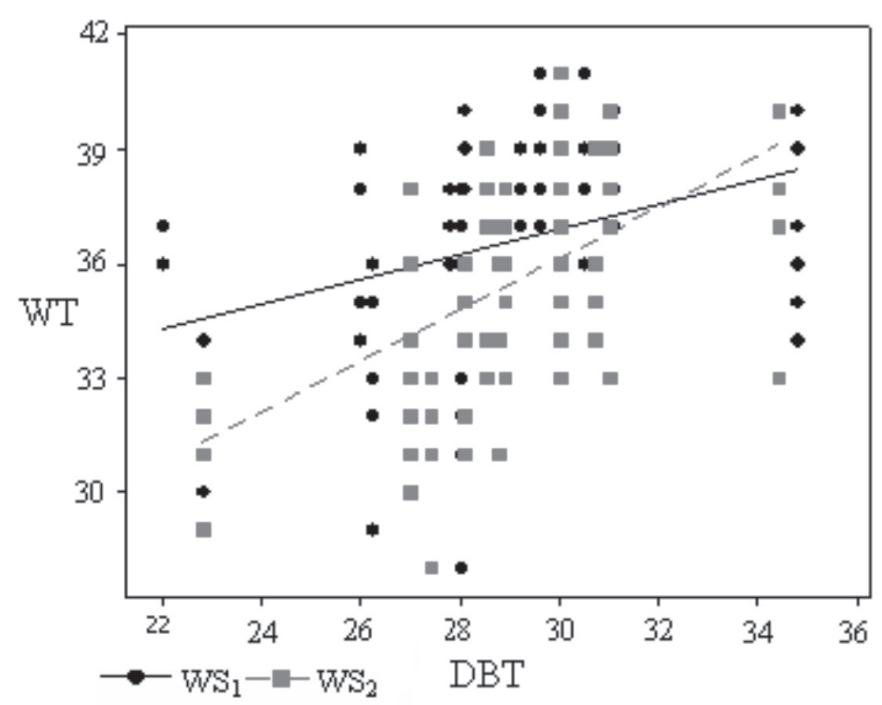

Figure 6. Influence dry bulb environmental temperature on the wattle temperature of 96-day-old turkeys at two wind speed ranges $\left(W S_{1}=0.3\right.$ to $0.6 \mathrm{~m} \mathrm{~s}^{-1}$ and $\mathrm{WS}_{2}=1.2$ to $1.6 \mathrm{~m} \mathrm{~s}^{-1}$ ).

According Lin et al. (2005), the effect of relative humidity on the ratio between peripheral and core temperatures of broiler chickens is related to age and depends on air temperature. Thermal balance 


\section{Turkey Wattle Temperature Response to Distinct Environmental Factors}

Even though WT data dispersion at both WS ranges were similar when $\mathrm{RH}$ was analyzed (Figure 7), the slope of the adjusted lines shows the effect of the interaction of RH with WS 2 on WT. Moreover, WT responses were practically the same at both wind speed ranges when DBT was higher (Figure 8), but the analysis revealed a correlation between DBT and $\mathrm{WS}_{2}$. The steep slope of both lines indicates that both $\mathrm{RH}$ and DBT are correlated with WT at both wind speed ranges.

In the present study, results were different according to turkey age. The WT response atall ages $(61,96$, and 131 days) depended on positive forced wind speed $\left(W S_{1}\right.$ and $W_{2}$ ), according to the different DBT and RH combinations. There was a higher effect of interaction of RH with WS on the WT both at61 and 131 days. The interaction between DBT and WS affected the WT response of 96- and 131-old male turkeys. BrownBrandl (1997) evaluated the physiological responses of male tom turkeys of five different ages ( 5 to 20 weeks) exposed to five ambient dry bulb temperatures (25$40{ }^{\circ} \mathrm{C}$ ) and relative humidity values (40-80\%), and found that $\mathrm{RH}$ had higher overall impact than DBT on both turkey's respiratory rate and body temperature, differently from the results of the present experiment. However, that author also found highly positive correlation between $\mathrm{RH}$ and DBT in 20-week-old turkeys, in agreement with the findings of the present study.

The results show that the use of forced ventilation in turkeys' rearing environment may is a good strategy to reduce heat stress, as previously suggested for broiler chickens in literature (Mitchell \& Kelley, 1983; Timmons andHillman,1993; Bottcher \& Czarick,1997; Czarick \& Lacy, 1999; Aradas et al., 2005; Hurwitz et al., 1980; Cavalchini, 1985; Yahav et al., 1995; Martrenchar, 1999; Teeter \& Belay, 1996).

The impact of the wind speed on wattle temperature depended on turkeys' age and was correlated with rearing environment variables (DBT and $\mathrm{RH}$ ), as also found by Brown-Brandl \& Beck (1998). In addition, Veldkamp et al. (2000) reported that environmental temperature have a marked effect on feed intake, body weight gain, feed conversion ratio, and carcass yield of turkeys.

\section{CONCLUSIONS}

Wind speed influenced turkey wattle temperature as a function of environmental dry bulb temperature and relative humidity, as well as of turkeys' age. 


\section{REFERENCES}

Aradas MEC, Nääs IA, Salgado DD. Comparing the thermal environment in broiler houses using two birds densities under tropical conditions. Agricultural Engineering International: CIGR Ejournal 2005;7(BC 03 017):1-9.

Bottcher RW, Czarick M. Tunnel ventilation and evaporative cooling for poultry. North Carolina: Cooperative Extension Service; 1997.

Brown-Brandl TM, Beck MM. Temperature-humidity effects on growing male turkeys. Nebraska: Cooperative Extension Work, University of Nebraska; 1998.

Cavalchini, LG. El Pavo. Madrid: Mundi-Prensa; 1985.

Czarick M, Lacy PM. Importance of air movement vs. bird age [technical bulletin]. Athens: University of Georgia of Agriculture; 1999. 16p.

Czarick M. The best performing tunnel fans. Poultry Housing Tips 2006;18(5):4.

Gates RS, Zhang H, Colliver DG, Overhults DG. Regional variation in temperature humidity index for poultry housing. Transactions of the ASAE 1998;38(1):197-205

Havenstein GB, Ferket PR, Qureshi MA, Grimes JL. Comparison of the performance of 1966 vs. 2003-type turkeys when fed representative 1966 and 2003 turkey diets: 1. Growth rate, livability, and feed conversion. Poultry Science 2007;86:232-240.

Hellickson MA, Butchbaker AF, Witz RL, Bryant RL. Performance of young turkey as affected by environmental temperature. Transactions of the ASAE 1967; 10:793-795

Hurwitz S, Weiselberg M, Eisner $U$. The requirements and performance of growing chickens and turkeys as affected by environmental temperature. Poultry Science 1980;10(10):2290-2299.

Hurwitz S, Bengal I. Energy Use and performance of young turkeys kept under various constant and cycling environmental temperatures. Poultry Science 1982;61(6):1082-1086.

Lin H, Zhang HF, Du R. Thermoregulation responses of broiler chickens to humidity at different ambient temperatures. II. Four weeks of age. Poultry Science 2005;84:1173-1178.

Martrenchar A. Animal welfare and intensive production of turkey broilers. World Poultry Science 1999; 55:143-152.

MINITAB 15 Statistical software; 2005 - [cited 2006 Nov 20]. Available from: http://www.minitab.com/products/minitab/.

Mitchell HH, Kelley MAR. Estimated data on the energy, gaseous, and water metabolism of poultry for use in planning the ventilation of poultry houses. Journal of Agricultural Research 1983;47:735-748.

Morello GM, Mende AS, Moura DJ. Efeito da velocidade do vento na temperatura de barbela de perus aos 61 dia (effect of air velocity on wattle temperature of 61 day old turkeys). Brazilian Journal of Poultry Science 2007;9:17-18
Morgan KN, Tromborg CT. Sources of stress in captivity. Applied Animal Behaviour Science 2007;102:262-302.

Nääs IA. Aspectos físicos da construção no controle térmico do ambiente das instalações. Anais da Conferência Apinco, Ciência E Tecnologia Avícola; 1994; Campinas, São Paulo. Brasil: FACTA; 1994.

Nixey C, Grey TC. Recent advances in turkey science. London: Butterworths; 1989. 285p.

Prinzinger R, Presmar A, Schleucher E. Body temperature in birds. Comparative Biochemistry and Physiology 1991;99:499-506

Sasseville VG, Miller B, Nielsen SW. A Pathologic study of wild turkeys in Connecticut. Cornell Veterinary 1988;78:353-364.

Teeter RG, Belay T. Broiler management during acute heat stress Animal Feed. Science Technology 1996;58:127-142.

Timmons MB, Hillman PE. Partitional heat losses in heat stressed poultry as affect by wind speed. Livestock Environment 1993;1:265.

UBABEF...Relatório.Anual.2014 - [cited 2015 Fev 24]. Available from http://www.ubabef.com.br/files/publicacoes/8ca705e70f0cb110ae3ae d67d29c8842.pdf.

Veldkamp T, Ferket PR, Kwakkel RP. Interaction between ambient temperature and supplementation of synthetic amino acids on performance and carcass parameters in commercial male turkeys. Poultry Science 2000;79:1472-1477.

Yahav S, Druyan S, Rusal M, Shinder D. Diurnally cycling temperature and ventilation affect young turkeys' performance and sensible heat loss. Journal of Thermal Biology 2011;36:334-339.

Yahav S, Goldfeld S, Plavnik I, Hurwitz S. Physiological response of chickens and turkeys to relative humidity during exposure to high ambient temperature. Journal Thermal Biology 1995;20(3):245-253.

Yahav S, Hurwitz S, Rozenboim I. The effect of light intensity on growth and development of turkey toms. British Poultry Science 2000;41:101-106.

YahavS, Luger D, Cahaner A, Dotan M, Rusal M, HurwitzS. Thermoregulation in naked neck chickens subjected to different ambient temperatures. British Poultry Science 1998;39(1):133-138.

Yahav S, Plavnik I. Effect of early age thermal conditioning and food restriction on performance and thermotolerance of male broiler chickens. British Poultry Science 1999;40:120-126.

Yahav S, Shinder D, Tanny J, Cohen S. Sensible heat loss: the broiler's paradox. World's Poultry Science Journal 2005;61(3):419-434

Yahav S. Domestic fowl-Strategies to confront environmental conditions. Poultry Avian Biology Review 2000;11:81-95.

Yahav SA, Straschnow D, Luger D. Ventilation, sensible heat loss, broiler energy, and water balance under harsh environmental conditions. Poultry Science 2004;83:253-258. 